\title{
Robotic arm material characterisation using LIBS and Raman in a nuclear hot cell decommissioning environment
}

DOI:

10.1016/j.jhazmat.2021.125193

\section{Document Version}

Accepted author manuscript

Link to publication record in Manchester Research Explorer

\section{Citation for published version (APA):}

Coffey, P., Smith, N., Lennox, B., Kijne, G., Bowen, B., Davis-johnston, A., \& Martin, P. A. (2021). Robotic arm material characterisation using LIBS and Raman in a nuclear hot cell decommissioning environment. Journal of Hazardous Materials, 412, [125193]. https://doi.org/10.1016/j.jhazmat.2021.125193

\section{Published in:}

Journal of Hazardous Materials

\section{Citing this paper}

Please note that where the full-text provided on Manchester Research Explorer is the Author Accepted Manuscript or Proof version this may differ from the final Published version. If citing, it is advised that you check and use the publisher's definitive version.

\section{General rights}

Copyright and moral rights for the publications made accessible in the Research Explorer are retained by the authors and/or other copyright owners and it is a condition of accessing publications that users recognise and abide by the legal requirements associated with these rights.

\section{Takedown policy}

If you believe that this document breaches copyright please refer to the University of Manchester's Takedown Procedures [http://man.ac.uk/04Y6Bo] or contact uml.scholarlycommunications@manchester.ac.uk providing relevant details, so we can investigate your claim.

\section{OPEN ACCESS}


1 Robotic arm material characterisation using LIBS and Raman in a nuclear hot cell 2 decommissioning environment

3 Paul Coffey ${ }^{1,2}$, Nick Smith ${ }^{3,4}$, Barry Lennox ${ }^{5}$, Gerben Kijne ${ }^{6}$, Bob C. Bowen ${ }^{7}$, Adrian Davis4 Johnston $^{7}$ and Philip A. Martin*1,2

5

6

7

8

${ }^{1}$ Department of Chemical Engineering and Analytical Science, University of Manchester, Manchester, M13 9PL, UK.

${ }^{2}$ Photon Science Institute, University of Manchester, UK.

${ }^{3}$ Department of Mechanical, Aerospace and Civil Engineering, University of Manchester, Manchester, M13 9PL, UK.

${ }^{4}$ National Nuclear Laboratory, UK.

${ }^{5}$ Department of Electrical \& Electronic Engineering, University of Manchester, UK.

${ }^{6}$ Pixel Mill Digital, Manchester, UK.

${ }^{7}$ Nuvia Ltd., Cumbria, UK.

*Corresponding author:

Email address: Philip.Martin@Manchester.ac.uk; Tel.: +44 1613065779

\section{Abstract}

Material characterisation in nuclear environments is an essential part of decommissioning processes. This paper explores the feasibility of deploying commercial off the shelf (COTS) laser induced breakdown spectroscopy (LIBS) and Raman spectroscopy, for use in a decommissioning hot cell environment, to inform waste operation decision making. To operate these techniques, adapters and probes were designed and constructed, for each instrument, to form tools that a robotic arm could pick up and operate remotely from an isolated control room. The developed instrumentation successfully returned live measurement data to a control room for saving and further analysis (e.g. material classification/identification). Successful testing of the solutions was performed for contact LIBS, contact Raman and stand-off Raman on a PaR M3000 robotic arm, in a simulated hot cell environment and the limitations identified. Data obtained by the techniques are analysed, classified and presented in a 3D virtual environment. The spectral data collected by a basic COTS LIBS showed potential for use in contamination identification (beryllium is used as example). Potential for COTS, LIBS and Raman in decommissioning is established and improvements to the hardware, the measurement processes and how the data is stored and used, are identified.

\section{Keywords:}

Robotics, LIBS, Raman, remote analysis, material characterisation, nuclear environments, decommissioning 
An era of nuclear decommissioning is underway, as power plants, sites and facilities built for a multitude of nuclear activities are dismantled and undergo clean-up activities. To deal with legacy waste efficiently and safely, the chemistry and composition of waste must be identified, so the most suitable waste management operations and processes can be selected, during, for example, pre-treatment, treatment, conditioning, immobilization, storage [1-6], and eventual disposal, which are each made more complex by mixed wastes.

Combining robotics with waste identification processes that would otherwise expose workers to hazardous environments, is a logical evolution. Robotic platforms exist for many tasks in the nuclear industry [7], such as welding [8], cutting [9], surveying structural degradation [7, 10], cleaning [7], radiological surveys [11-17] and entering sites of accidents [18]. Robotic platforms deployed in nuclear environments, now come in many forms and are becoming more complex and capable. Platforms include, ground rovers [14], robotic arms [19, 20], aerial drones [11-13, 15], wall climbing [21], floating[22], submersibles [16], shape-changing [23] and snakes [7, 24]. Robotic platforms are used to make a range of assessments, including radiometry, x-ray, radar, acoustic and ultrasonic inspection $[16,25,26]$, imaging and spatial imaging. Robotics used for assessments of materials and environments are only as useful as the information they return. Consequently, to be more useful, robotic platforms need advancements in characterisation tools that they can easily use and carry.

A move towards more automated characterisation will lead to benefits such as, reduced labour, increased safety, measurements that are less limited by acquisition time (or patience of the operator), resulting in an overall reduction in time and costs for decommissioning. Additional benefits include improved consistency in the quality of data collected and more reliable audit trails through automated record keeping of the measured data.

Within nuclear facilities, both active and non-active, waste requires identification. Some nonactive waste will be highly reactive, corrosive, toxic, harmful, or carcinogenic (including asbestos, many heavy metals and beryllium, etc.), whilst encapsulation or vitrification of higher activity waste in order contain it safely requires knowledge of what the waste is, so the chemistry related to long term storage options can be evaluated. For example, cementitious matrices used extensively to encapsulate waste will react with elements such as aluminium, magnesium, uranium and beryllium [27-29] producing reaction products such as hydrogen that can generate pressure and possibly expand the waste form, posing an explosion risk [30]. Consequently, assessments of materials by in-situ techniques are not limited to direct measurements of the original waste, but also applies to any materials likely to be placed into contact with waste during decommissioning to identify anomalies (e.g. incorrect, or incompatible materials), to enhance safety and prevent leaks and ruptures that generate significant quantities of additional waste. Another benefit of quickly and easily identifying the type of waste material, is that the various waste forms can be segregated, making treatment and subsequent storage significantly more cost effective.

Material characterisation is important in guiding decisions on typical waste management and decommissioning operations such as, segregation, immobilisation and packaging, but knowing what the waste is may be difficult. Legacy documentation for waste can be inadequate, or nonexistent and details of facilities undergoing decommissioning incorrect [31,32]. Materials may have changed chemically and physically, possibly by irradiation, contamination, chemical 
reactions, or through ageing effects and may be mixed with other degraded waste materials. Identification of waste is often done by manual collection of a sample and having it sent to a central lab which is slow, has associated risks, creates additional waste, is expensive (it can become prohibitively expensive to do comprehensive sampling, when a nuclear reprocessing, storage and decommissioning site can have over 200 facilities and over a 1000 buildings) and may be impossible if the regulatory maximums for transporting dangerous materials are likely to be exceeded. Consequently, it would be advantageous to do as much identification in-situ, with as minimal sample disruption as possible. In-situ assays could begin to classify and subdivide waste into relevant streams, minimising the number of samples that require laboratory analysis.

Over recent years there has been emphasis on better waste characterisation, in a bid to recycle and reuse more, to reduce the amount of waste that is disposed of and thus to extend the life of disposal facilities. In addition to structural materials, such as concrete, spoil and soils. A vast amount of support materials is used in nuclear facilities, resulting in many forms of contaminated materials, including many types of plastics (e.g. tools, coatings, laminates, personnel protection equipment, lab-ware, glove boxes, sheeting, etc.), a large range of chemicals and many metals. If decontamination friendly materials can be identified and cleaned, waste volumes can be reduced, or lower radiological classifications of the waste can be made, resulting in cheaper waste routes. For example, to achieve the most efficient, or correct (chemical, electrochemical, ozone, etc.) cleaning process of contaminated metals, with the least amount of new waste being produced, requires knowledge of the metal type [33-35]. In addition to plastics being of importance, they can be used as surrogates in this study for many chemicals and organic materials. Monitoring of materials is of interest for plastics used for encapsulation of low-level waste and of sealants (and coatings) used on concrete structures, where sealants minimise water soluble radionuclides penetrating deeply into concrete. With properly maintained sealed concrete, the amount of primary concrete and secondary cleaning waste that would otherwise be categorised as nuclear waste can be reduced.

Laser induced breakdown spectroscopy (LIBS), and Raman spectroscopy may provide a solution for identification of materials in nuclear environments with little, or no, sample disruption. Instruments based on these techniques can be mounted on different robotic platforms and assist in decommissioning. LIBS can be used to determine the elemental composition of samples. It works by focusing a laser at the sample to achieve a high concentration of energy, this energy ablates a small amount of material and forms a plasma. Light emitted from the resulting plasma plume is detected as the plasma cools and is analysed for the characteristic wavelengths of each element. Raman spectroscopy is an analytical technique based on inelastic laser light scattering, where the wavelength of the scattered light from a Raman active sample gives information on the sample's molecular vibrations and thus species identification from the molecular fingerprint.

Multivariate analysis techniques have been applied to LIBS to enhance sensitivity and to discriminate different materials when the elemental composition of samples is similar. For many elements LIBS has limits of detection (LOD) in the low parts per million (PPM). In stand-off studies of explosives and chemical compounds, multivariate analysis techniques discriminated samples with minor differences in atomic and molecular LIBS emission intensities, where univariate methods could not discriminate between the samples [36-38]. Horsfall et al. demonstrated an analysis workflow based on multivariate analysis that could 
discriminate between nuclear grade graphite and other carbonaceous wastes during nuclear decommissioning and waste management of graphite wastes [39]. Combining Raman and LIBS data sets in to multivariate techniques can further enhance discrimination, for example a study of pigments and inks, used multiple multivariate techniques and found every analysis to be superior to those obtained with the individual Raman or LIBS data sets alone [40].

LIBS and Raman have been combined by NASA for use on Mars to study geological signatures [41] and are techniques that have been used independently for nuclear studies. For nuclear studies the techniques are predominantly lab based [39, 42], with some interesting on-site LIBS deployments by Whitehouse et al. [43, 44]. However, in-field application remains low and (until now) the techniques have not been demonstrated on robotic platforms for use in decommissioning.

Deployment of characterisation instrumentation on a robotic arm has many challenges that need to be considered. For example, the form and weight of the instrument, the centre of mass, robustness, power distribution, communication methods, electromagnetic interference, control over the settings and operation, format of the data received, safety concerns associated with the technique, and how to safely target, align and potentially make contact with a sample. Good optical alignment for characterisation can also be critical, particularly for closely focused measurements where the depth of field is important. For a nuclear environment, there are additional issues to consider such as ionising radiation, contamination, and security concerns and disruption of wireless communications.

Ionising radiation can cause issues such as, failure and erratic behaviour of electronics [45, 46], optical materials (and optical fibres) can have radiation induced attenuation [47-50], optical fibres can lose tensile strength [47, 51] and materials used for construction can become brittle and break. The sensitivity of sensors such as CMOS and CCD arrays can reduce, noise and the dark current can increase [45, 52]. Due to poor availability, higher cost, or lower performance [46] of radiation hardened components, commercial-off-the-shelf (COTS) instruments are rarely radiation hard. To deploy COTS instrumentation, not designed for remote operation on a robot arm (such as a hand-held LIBS) in a nuclear environment, requires the development of reliable workarounds, selection of, or swapping to more resistant components where possible and avoidance of ionising radiation, for example by locating sensitive equipment away from any radiation sources.

This work aims to explore the feasibility of robotic arm-mounted COTS laser induced breakdown spectroscopy (LIBS) and Raman spectroscopy, for use in a generic decommissioning hot cell environment to inform waste operation decision making, where standard material characterisation techniques and methods (including those for solids, liquids gasses, metals and non-metals), such as sample collection and off-site analysis are not possible. COTS devices are of interest due to their low cost, ease of replacement, reduced need for expert users, robustness, compact size, reduction in development time and are often more trusted from a safety perspective by those that regulate deployment activities, as they have often received various certification standards. In the UK civil nuclear industry, for safety reasons, deployment of new technologies in a radioactive environment on a nuclear licenced site can only be undertaken if feasibility has been proved, following technology readiness assessments levels [53]. Feasibility of developed LIBS and Raman spectroscopy must therefore be proved in a non-radioactive setting using simulated environments and surrogate materials. Quantification 
of materials and their spatial distribution is not part of this initial feasibility study. The study is part of a wider project, TORONE (Total characterisation by Remote Observation in Nuclear Environments) [54] where different sensor systems including radiation detectors are developed for integrated use on automated robotic platforms.

The paper begins by describing the design of adapters and probes, for each characterisation instrument, such that they can be deployed on a robotic arm. The adapters and probes are then integrated onto the robotic arm in a simulated active hot cell, where they are used to take measurements of different materials, whilst being operated remotely from an isolated control room. The performance and potential of the COTS LIBS and Raman measurements are assessed with limitations and solutions discussed. For the hand-held LIBS, its ability for contamination detection is explored using non-radioactive aluminium and beryllium, which are common materials in nuclear decommissioning locations, but which are here used firstly to represent the many other materials connected with nuclear decommissioning, and secondly as surrogates for radioactive aluminium and beryllium. Characterisation of beryllium is particularly important as it is highly toxic [55]. It is used in neutron reflector and moderator applications [56] in smaller fission reactors and because of its toxicity is an element that needs special consideration during decommissioning of fission, fusion and weapons facilities [5759]. To demonstrate how the measured data can be more efficiently presented for better decision making, we show how the data obtained by the techniques are analysed, classified and presented in a database-focused, 3D virtual, visualisation-rich environment.

\subsection{Experimental methodology and instrument design}

\subsection{LIBS instrumentation}

\subsubsection{Hitachi High-Tech LIBS}

The system developed for deployment in this study was based on a Hitachi High-tech (HHLIBS) hand-held LIBS which was designed to be a contact measurement instrument. The HHLIBS is programmed for metal grade identification from in-built libraries. The instrument uses a passive Q-switch laser at a wavelength of $1064 \mathrm{~nm}$, with a pulse length of $\sim 2.5 \mathrm{~ns}$, a repetition rate of $\sim 8 \mathrm{kHz}$, a maximum energy of $60 \mu \mathrm{J}$ per pulse. A measurement is made using a linear scan of accumulated shots over an area of $\sim 2 \times 0.1 \mathrm{~mm}^{2}$. The gate-width and the delay time for analysis is unknown for this commercial device. The spectral range was determined to be in the region of $\sim 237-516 \mathrm{~nm}$. The spectral resolution is discussed in section 3.1.2. The focal length of the final laser optic is approximately $2 \mathrm{~cm}$, the unit has a weight of $\sim 1.5 \mathrm{~kg}$ and is battery powered with an operational time of $\sim 9$ hours.

Although LIBS can be employed in a stand-off manner with higher power lasers and larger optics. Hand-held devices are optically focused for very close measurements, this is a limitation of all known hand-held systems and is due to the low-power solid state lasers, the human element and laser safety, but have advantages such as low cost, low energy usage and compact size. Contact allows for straightforward control of distance, a method for maintaining position (which improves measurement reliability) and reduces potential exposure of the operator to the LIBS laser.

In LIBS measurements, chemical and physical properties of a sample affect the plasma composition, through a process known as the matrix effect. This prevents the application of universal elemental calibration curves to all samples, consequently LIBS instruments are often 
calibrated based on known samples and standards (at fixed distances). Basic calibration methods based on calibration curves and more advanced strategies used to minimise problems such as matrix effects are discussed by Haddad et al [60]. Multivariate analysis techniques are superior methods for determining concentrations, and for classifying and separating materials. Multivariate methods applied to LIBS analysis include, principal component analysis, partial least squares discriminate analysis, soft independent modelling of class analogy, random forest, support vector machine, artificial neural networks, principal component regression, multilinear regression, partial least squares regression and support vector regression [40, 60-62].

The HH-LIBS provides a semi-quantitative, statistically calculated results of sample type and elemental composition. The methods used by the HH-LIBS to determine the sample type and composition is proprietary and not available to the authors. One approach to estimate the sample type and elemental composition could be based on the intensity of elemental peaks, relative to calibration standards of known elemental composition. Element identification of spectral lines (of raw spectra) was carried out based on the NIST Atomic Spectra database [63] and the SpecLine software [64].

\subsubsection{LIBS mount design}
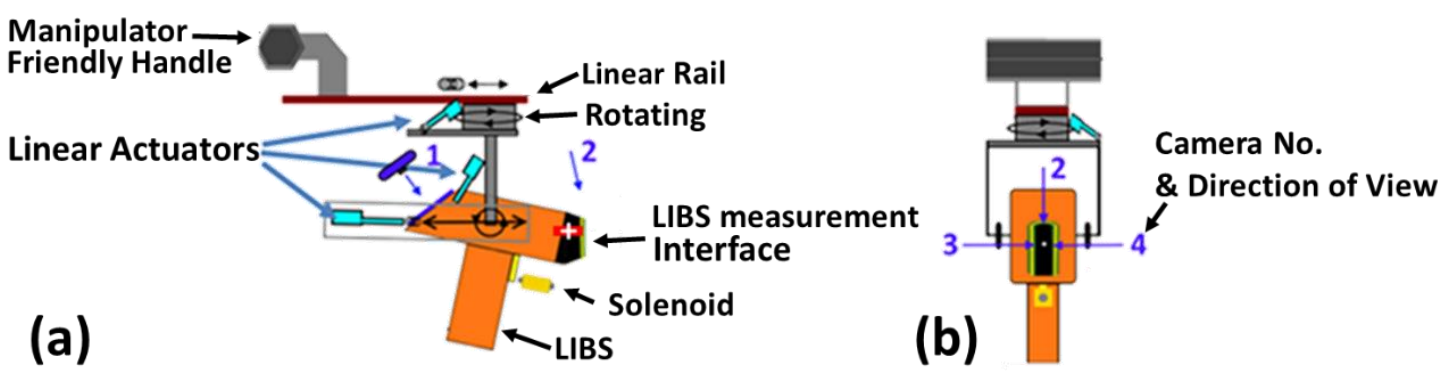

Figure 1. Simplified schematic of hand-held LIBS within the robotic mount (a) side perspective, (b) front perspective. Camera 1 pointing at LCD screen; Camera 2, $3 \& 4$ pointing at LIBS measurement interface; Targeting cross hair lasers, sit symmetrically either side of the laser head indicated by a "+" sign.

The robotic mount for the HH-LIBS (Figure 1) allows the LIBS measurement interface to contact the sample, take a measurement from the robotic arm and return the data to the control room for saving and viewing. The LIBS mount is held by the grippers of the robotic arm, via the manipulator friendly handle. The LIBS robotic mount is designed to position samples flat against the entire LIBS measurement interface, or against the measurement aperture alone (i.e. for small samples, or for edges of larger samples, or for samples with irregular shapes).

The developed mount can pan, rotate and move the LIBS kit forwards. Each axis is driven by a compact linear actuator, with positional feedback and stall protection. The axis for moving the instrument forwards is used for final approach, moving perpendicular to the desired sample interface. Each actuator had a spring/cushion to dampen any impacts.

Cameras 2, $3 \& 4$, in Figure 1, were operated over 25 metre cables and used to monitor the LIBS head alignment, with respect to the sample. Two cross hair targeting lasers, attached to either side of the LIBS head, were focused and positioned to cross at the sample measurement position. Once in position, the laser head would move in for final approach using the axis that moves perpendicular to the sample interface. 
Software was developed for control room operation of the HH-LIBS and was programmed in Labview. The software provided control over movement of the mount and operation of the LIBS device, emulating user operation of the device. The software displayed four live video feeds: one camera recorded the LCD interface reporting automatically analysed data and the other three cameras were directed at the sample interface. A copy of the settings used and stills from all live video feeds were recorded at the end of a measurement and made available for further processing. Raw spectral data could not be sent directly back to the control room, as this required a sequence of non-trivial physical steps, an unfortunate limitation of some COTS devices.

\subsubsection{Benchtop LIBS}

An Applied Photonics LIBS-8 (LIBS-8) instrument was used for comparison with the HHLIBS. The LIBS-8 instrument utilises an electro-optically Q-switched Nd:YAG pulsed laser, that operates at a wavelength of $1064 \mathrm{~nm}$, up to $20 \mathrm{~Hz}$ (model NL301G), with a maximum 200 $\mathrm{mJ} /$ pulse energy, with a temporal laser beam width of 3-6 ns. The laser pulse energy was set to $100 \mathrm{~mJ}$ and measurements were taken as a single shot pulse. The light emitted from the cooling plasma was collected by 8 plasma focused collimators, with focal lengths of $125 \mathrm{~mm}$ and coupled to 8 Avantes spectrometers with a combined wavelength range of 185-1011 nm. The gate-width was $1.1 \mathrm{~ms}$ and the delay time for analysis was fixed at the minimum value of 1.27 $\mu \mathrm{s}$, a standard time delay. Analysis of spectra from a Hg lamp and measuring the FWHM of the spectral lines indicated that the resolution over the spectral range was, $\sim 0.07 \mathrm{~nm}$ below a wavelength of $360 \mathrm{~nm}, \sim 0.1 \mathrm{~nm}$ FWHM between 360-530 nm and a FWHM raising from $\sim 0.1$ to $0.2 \mathrm{~nm}$ from 530 to $1011 \mathrm{~nm}$.

\subsection{Deployed Raman instrumentation}

\subsubsection{Raman spectroscopy setup}

Two different Raman probe mounts were deployed, a contact probe and a stand-off probe. The contact probe had the advantage of providing a self-contained dark environment, whilst the stand-off probe had a reduced, risk of contamination, total dose and instrument damage. Both probes were interchangeable and used the same umbilical, laser, spectrometer and software. The spectrometer and laser were coupled to the probe mounts using 16 meters of optical fibre. The spectrometer was a $-15^{\circ} \mathrm{C}$ cooled Ocean Optics QE Pro, covering a wavenumber range of $0-3000 \mathrm{~cm}^{-1}$, with a resolution of 7-11 $\mathrm{cm}^{-1}$. A continuous wave $785 \mathrm{~nm}$, wavelength stabilised diode laser (Innovative Photonic Solutions) with output power up to $500 \mathrm{~mW}$ was used.

\subsubsection{Contact Raman probe}




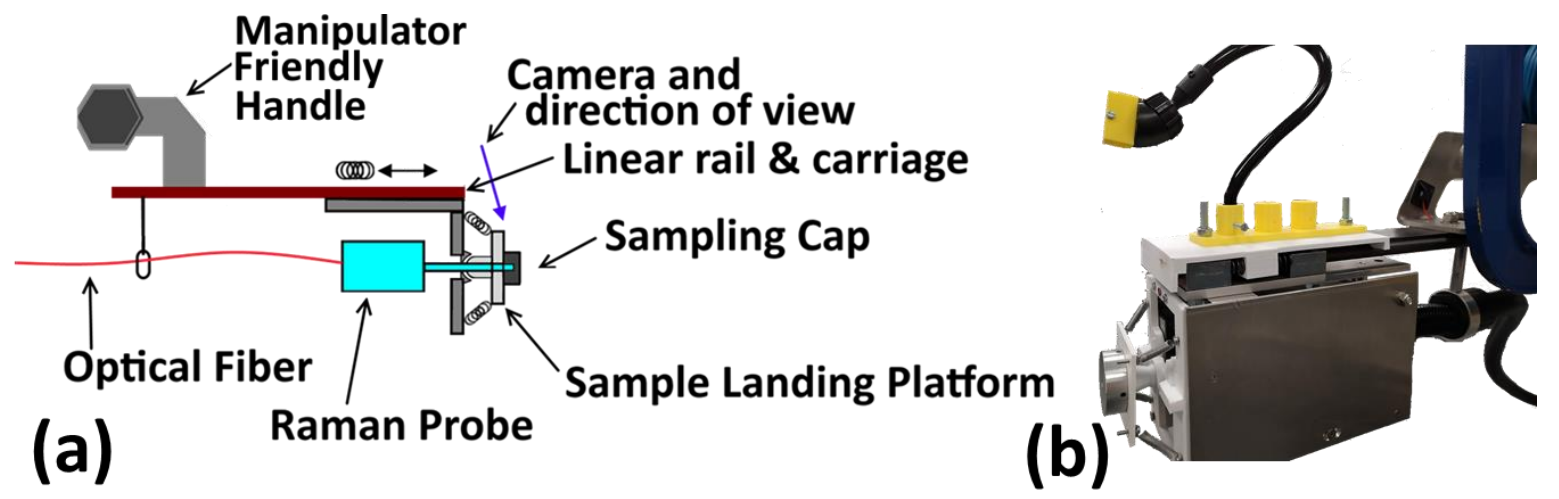

Figure 2. Contact Raman probe robotic mount for easier sample alignment, a) simplified schematic side perspective, (b) photo.

A contact Raman probe mount was developed for deployment in the simulated active hot cell, on the PAR M3000 robotic arm. The Raman probe was produced by InPhotonics, model RamanProbe [65] and was housed within the contact Raman mount, shown in Figure 2. The probe is widely used by multiple commercial Raman kit manufacturers and is easy to replace. The probe provides a $155 \mu \mathrm{m}$ spot at a wavelength of $785 \mathrm{~nm}$, with a focal distance of $7.5 \mathrm{~mm}$.

The Raman contact probe assembly requires sample contact to create a dark environment for the measurement. This dark environment was achieved using a stainless-steel sampling cap, shown in Figure 2. The sampling cap creates a reproducible probe to sample distance, for good focus and reproducible measurements. As the sampling cap is the only part that makes contact with the sample, it can be considered disposable. As the Raman probe is much lighter than the HH-LIBS, the design of the Raman robotic mount was simplified compared to the LIBS mount. To achieve alignment, the sampling cap was gently pushed against the sample and the "sample landing platform" (Figure 2) and the InPhotonics Raman probe self-aligns with respect to the sample. Once contact of the probe was confirmed, measurements were made, and a live data feed sent to the control room. The software, written in Labview, provided control over the measurement, laser and spectrometer settings, and automatically measured the background signal with the laser off and made a Raman measurement with the background subtracted. All the raw and processed Raman data, with a copy of the settings used and a still of the live video feed of the measured sample interface were then recorded, ready for further analysis.

\subsubsection{Stand-off Raman probe}

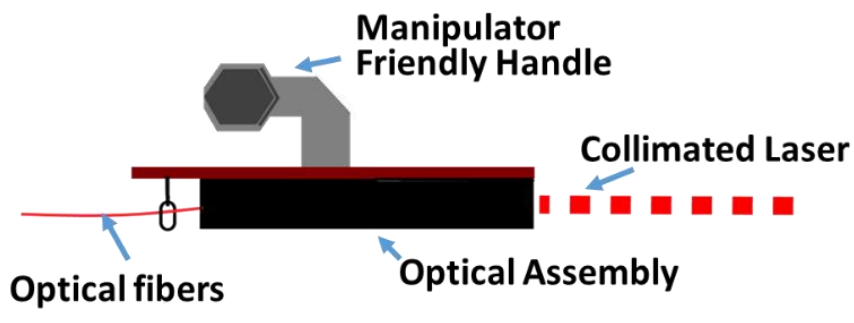

(a)

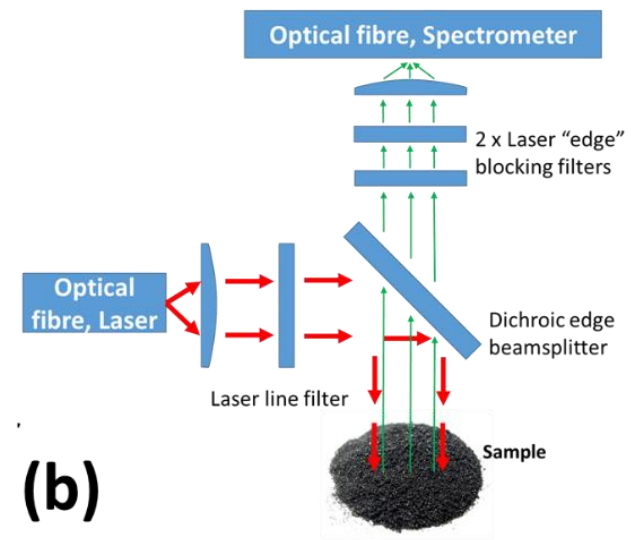


Figure 3. Schematic of (a) Stand-off Raman probe, (b) Stand-off Raman basic optical design (red lines represents laser, green line represents wavelength-shifted Raman signal).

The stand-off Raman probe uses an $11 \mathrm{~mm}$ diameter collimated laser beam, to measure the sample, therefore making it more of a point and shoot procedure, without the need to spend time focusing. The stand-off Raman probe was housed in a robust assembly that was picked up by the M3000 robotic arm, via the manipulator friendly handle (Figure 3(a)). The probe was constructed using Semrock laser line, edge and dichroic edge filters. The basic optical design of the stand-off Raman probe is shown in Figure 3 (b). The optics were designed for a one-inch diameter beam path and the dimensions of the optical housing/assembly were $5 \mathrm{~cm}$ by $9.5 \mathrm{~cm}$ by $36 \mathrm{~cm}$, without the manipulator friendly handle and additional umbilical support.

\subsection{Data Visualisation}

Measured characterisation data were mapped into a virtual environment created as part of the study by Pixelmill Ltd to enable the user to navigate around the facility. Data from raw point cloud scans were imported (LIDAR, CAD and photogrammetry) and processed into a 3D model. Data from the different characterisation instruments (e.g. LIBS and Raman) deployed on the robotic arm were added as separate layers within the virtual environment, and integrated with other data including radiological data obtained during a parallel study. All data were formatted to enable incorporation into a spatial database management system (SDBMS) as part of the "total characterisation by remote obsevation in nuclear environments" (TORONE) project [54].

\subsection{Materials}

Materials with known published spectra were used to gauge the performance of the instruments. These materials were chosen as representatives or surrogates of materials that are likely to occur in nuclear decommissioning hot cell locations. Where possible, five commercially available samples or more of each material were acquired from different manufacturers. Geometries studied included: flat plates (minimum size $\sim 10 \mathrm{~mm}^{2}$ ), 100 to 200 $\mathrm{mm}$ diameter cylinders and 20 to $30 \mathrm{~mm}$ round bar (or pipes). We highlight $20 \mathrm{~mm}$ round bar in this paper as it was deemed the most challenging to the study. Materials utilised during the study include those analysed by the LIBS, including aluminium (grade 5086), stainless steel (grade 304s and 3041), copper (grade C110), brass (grade CuZn39Pb1), beryllium $(99.5 \%$ purity), boron (99.5\%), undoped silicon wafers, zinc (99.9\%) and those analysed by Raman spectroscopy, including low-density polyethylene (LDPE), polyethylene terephthalate (PET), polypropylene (PP), polyethylether keytone (PEEK), polystyrene and high-density polyethylene (HDPE). For contact Raman tests of small particle sized samples, powdered poly(methyl methacrylate) (PMMA) and crushed acetaminophen (0.1 - $3 \mathrm{~mm}$ and $1-4 \mathrm{~mm}$ in particle size) were used. To represent materials of unknown composition within a generic hot cell, numerous industrial carbon steel parts also with unknown composition were also tested within the cell using LIBS, steel rods with a plastic coating labelled "rubberised coating" of unknown composition was tested using Raman spectroscopy.

\subsection{Environment and deployment setup}




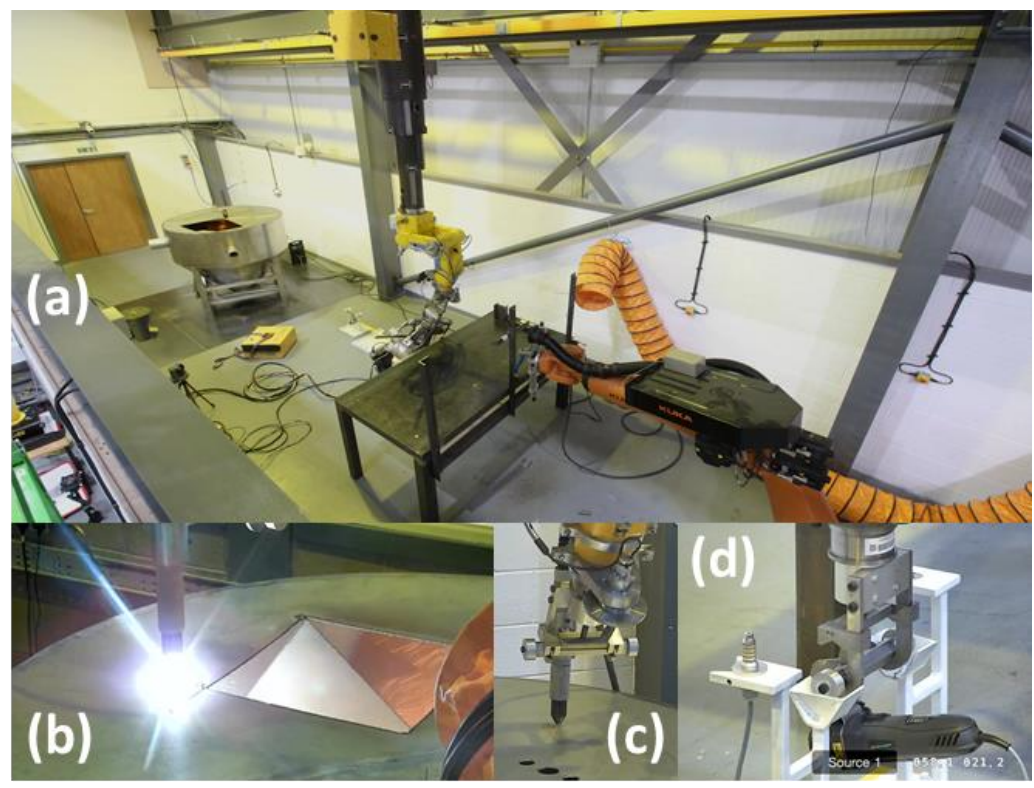

348 Figure 4 (a) Demonstration area simulating an active hot cell: this contains a waste sorting table 349 and an M3000 robotic arm; (b, c) robotic arm conducting plasma cutting; (d) tool holder used 350 for remote tool changing with dockable plugs.

(a)

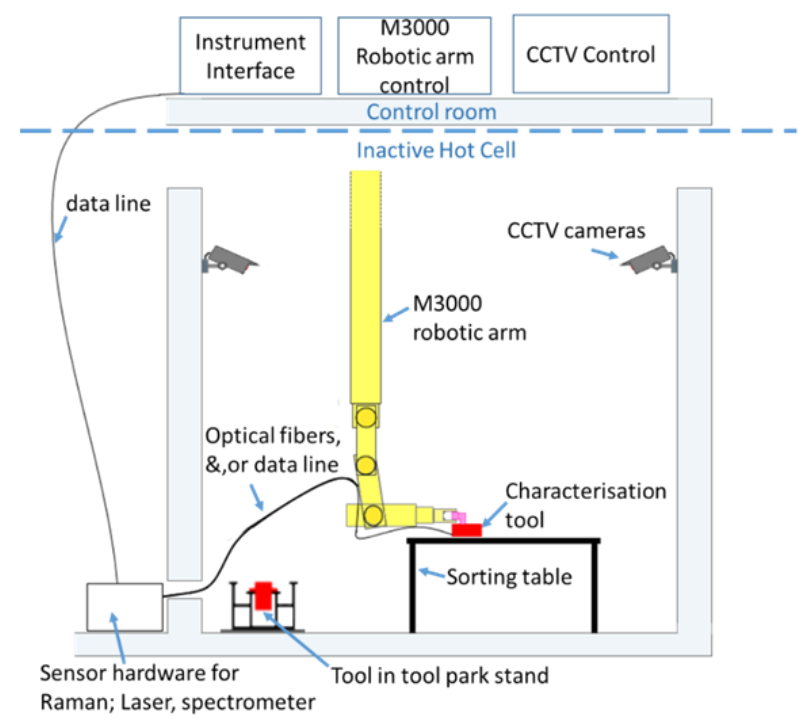

(b)

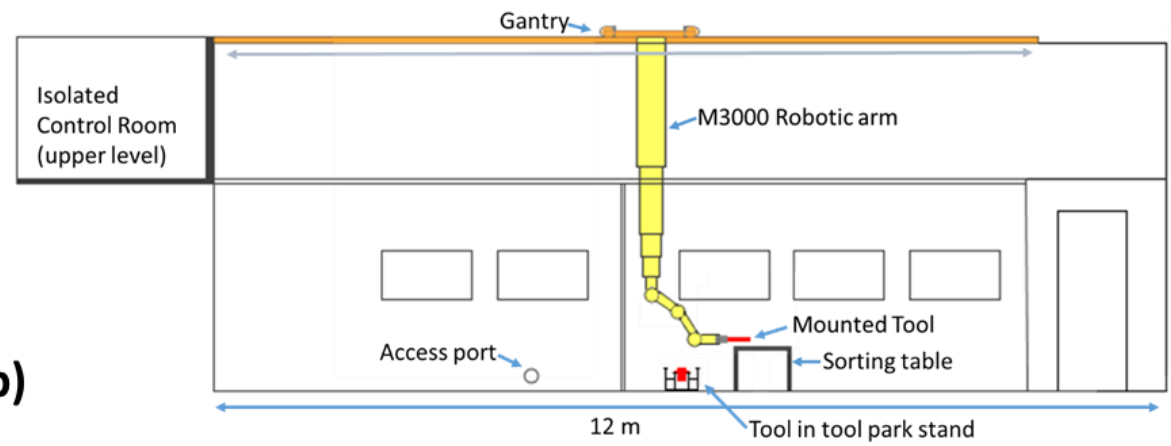

352 Figure 5. Schematic of the simulated active hot cell and control room and layout of the deployed characterisation instrumentation. (a) cross section front view, (b) side view. 
A simulated active hot cell (Figure 4(a)) at PaR systems provided a semi realistic environment to trial scenarios that required characterisation using a robotic arm. Activities were controlled and coordinated from the isolated control room, as shown in Figure 5. The scenario described in this paper was to identify materials and potentially problematic samples, on a waste sorting table, using the LIBS and Raman characterisation tools, prior to cutting, for better waste stream management. For example, sorting different metal grades and plastic types, or identifying problematic materials. Depending on the LIBS and Raman characterisation results, the robotic arm would proceed to select the most appropriate tool from the tool park stands (Figure 4(d) and 5), such as a plasma cutter, demonstrated in Figure 4 (b and c). For example, if contamination was detected, a reciprocating saw tool was selected instead of a plasma cutting tool, to minimise aerosol production during size reduction [66].

The robotic arm used for testing was a radiation hard PaR M3000, that has been used extensively to perform operations in hot cells and waste processing facilities [67]. The PaR Model 3000 robotic arm has a reach of $1156 \mathrm{~mm}$ and a hand capacity of $68 \mathrm{~kg}$. The relatively low weight of the devices and umbilical cabling (heaviest below $4 \mathrm{~kg}$ ) did not affect the motion of the robotic arm. In this study the arm was mounted on a gantry that could move across the length of the simulated active hot cell, as shown in Figure 5(b). The robotic arm could move up and down on a rotating telescopic mast, with shoulder, elbow and wrist pivots. The arm was controlled using a joystick from the control room, using inverse kinematics. To monitor deployment activities, four, $4 \mathrm{~K}$ pan, tilt and zoom CCTV cameras were mounted on the walls of the simulated active hot cell (Figure 5 (a)).

For LIBS, all the hardware was mounted on the robotic arm and a 25 metre dataline went from the LIBS mount to the control room. Raman measurements required 5 to 15 minutes, with increasing measurement times necessary for samples with weak Raman signals and longer when repeats were required. As a result, the total dose that Raman components could receive during a measurement was much higher than the equivalent LIBS measurement, which takes seconds (even with repeats). To mitigate the effects of gamma radiation, which can damage the electronics, optics and other materials used on the manipulator, the Raman laser and spectrometer were positioned safely outside of the simulated hot cell, next to an access port and optical fibres, of 16 metre in length, were fed in through the port (Figure 5) and attached to either of the two (contact or stand-off) Raman probes (section 2.2). The spectrometer, laser and camera feed were controlled from the control room, via 25 metre-long USB cables. This configuration reduces the cost of operating the equipment in a radioactive environment, where the sensitive Raman spectrometers and the laser, represents a significant capital cost, but the probes, which will receive a high gamma dose, are low-cost and potentially disposable.

\subsection{Results}

\subsection{LIBS}

\subsubsection{LIBS deployment}




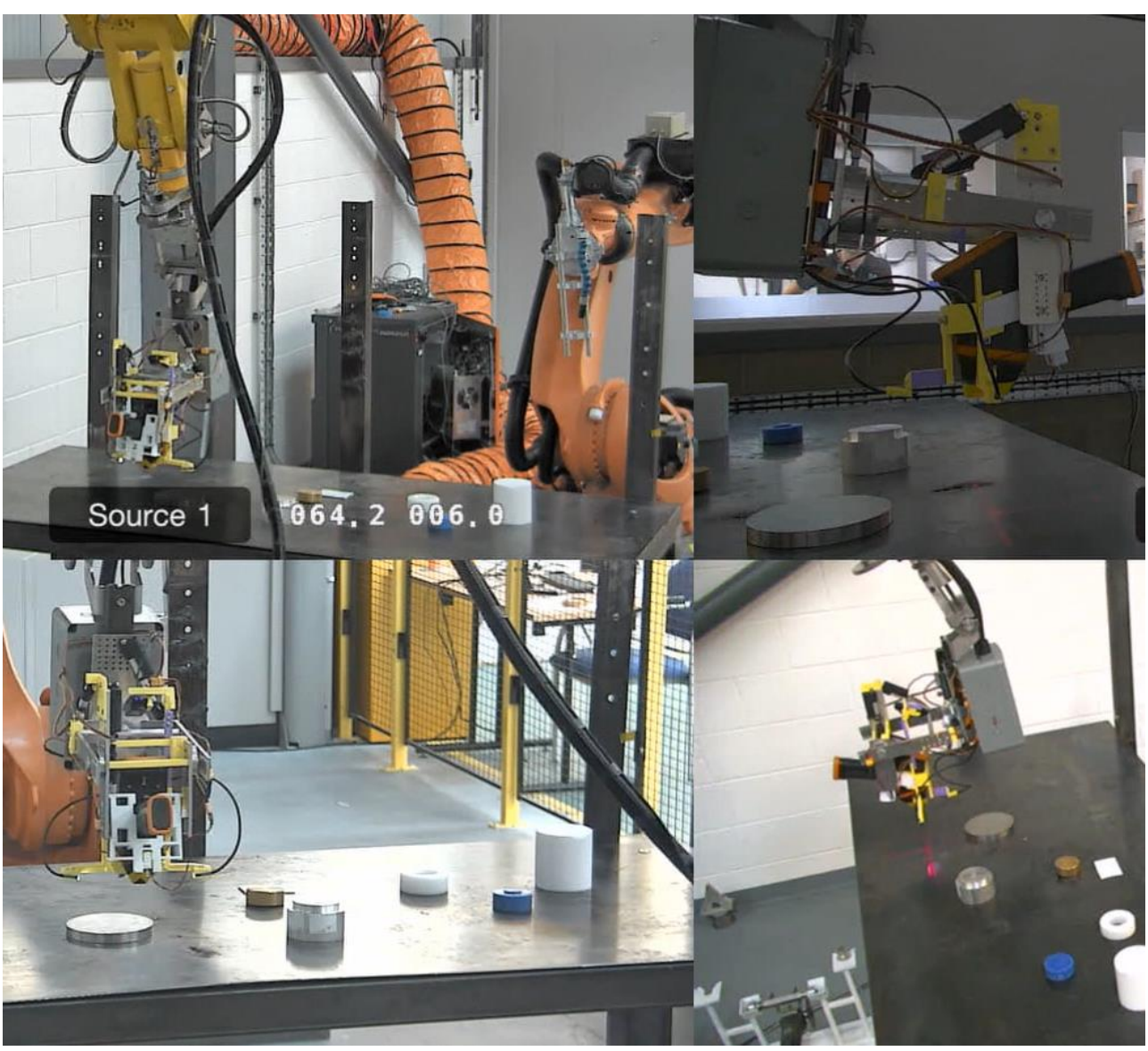

Figure 6. Control room views of LIBS deployed within the simulated hot cell, identifying samples on the sorting table.

The HH-LIBS plus docking mount, shown operating in Figure 6 within the simulated hot cell, was effective at measuring samples whilst being operated from the control room. Samples at multiple orientations (from vertical to horizontal) were tested and all were successful. The handle/grip of the HH-LIBS would occasionally become an obstacle, requiring repositioning of the sample, or a different approach to the sample. The finer control provided by the three axes of the LIBS robotic mount, made it easier and safer to use, than relying on the more forceful, coarser and possibly off axis movement provided by the robotic arm towards the samples. The crosshair targeting lasers used to position the unit to the measurement point, had multiple advantages. The crosshair lasers provided depth perception, when the control room CCTV cameras often could not. They could be used to gauge how far away the LIBS unit was from any objects, both for moving around the simulated hot cell, avoiding obstacles and positioning for a measurement. The targeting lasers could be used to determine how parallel objects were to the LIBS head interface. For example, when parallel to a sample, the vertical laser lines of the two cross-hair lasers were also parallel, otherwise they would be diverging, and the direction of divergence could then be used to guide the direction in which the LIBS head should be moved, with respect to the sample for alignment. The three cameras focused at the laser head interface (Figure 1 and 2) were essential for alignment, as this gave reassurance that everything was correct and allowed for minor alignment corrections as final approach was made (by the axis travelling perpendicular to the sample interface). Once mated with a sample the HH-LIBS measurements could be completed within a few seconds. 


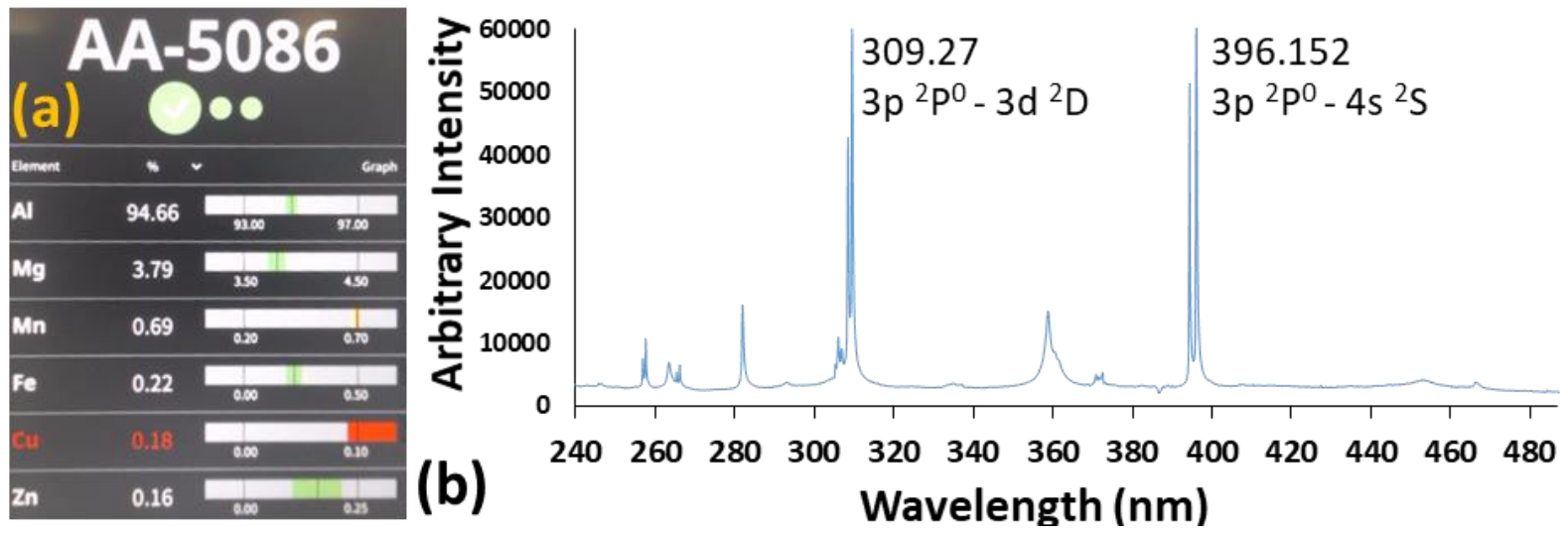

Figure 7. Hitachi High Tech LIBS, (a) on screen report of aluminium alloy grade fit of key elements sent back to the control room software, (b) example aluminium spectrum.

The HH-LIBS successfully identified all known samples accurately on the sorting table, including aluminium grade 5086 as shown in Figure 7, stainless steel grade 3041 and 304s (albeit both were identified as SS 304, with no sub grade identification available), copper C110 grade and brass grade $\mathrm{CuZn39Pb1.} \mathrm{Measurements} \mathrm{often} \mathrm{required} \mathrm{a} \mathrm{few} \mathrm{passes} \mathrm{of} \mathrm{laser} \mathrm{ablation}$ cleaning by the unit to get reproducible measurements. The laser ablation cleaning removed dirt and any oxide layers built up, but no additional intervention was required prior to a measurement. The curved surface of a stainless-steel round rod (20 $\mathrm{mm}$ diameter), did not influence the ability to achieve positive identification. It is worth noting, that the automated analysis routine of the device can get confused in some instances, for example, a painted wooden frame outputted incorrect results, with the quality of the indicated fit sometimes being too good for the misidentified result and quality of spectra obtained, for example identifying the material as a certain element when the spectrum was very noisy, with none of the elemental peaks present for the element in question. For samples outside the instrument's in-built material library's range, a visual check of the measured spectra was still required.

Many large industrial carbon steel parts with unknown composition were also tested within the cell. Most samples reported the same grade with reasonable consistency, but some parts would identify as different closely related steels. For example, a 1.0402 grade vs. a 1.0425 grade. The main difference between the two fitted grades was the detection of vanadium and niobium in the 1.0402 fit, where both vanadium and niobium had concentrations above the maximum percentages to be classified as a 1.0425 grade. Vanadium was measured at $0.38 \%$ and niobium was measured at $0.13 \%$ in the 1.0402 fit, where the maximum percentage of vanadium for a 1.0425 grade classification is $0.02 \%$ and $0.01 \%$ for niobium. Different regions of the same part would preferentially measure one of the two grades, indicating some sample inhomogeneity. The observed variation in the fitted grades of the carbon steel parts within the cell, may be due to the production process or quality of the parts, or the surfaces of the parts may have slightly different compositions than the bulk. In addition, some of the carbon steel parts may not conform perfectly to any of the standards stored in the HH-LIBS. For most waste sorting applications, the small differences observed in the reported grades would be unimportant.

\subsubsection{Performance assessment of HH-LIBS for contamination detection}


The HH-LIBS was not designed as a contamination detection tool, but for nuclear applications elemental identification of contamination is also required. Consequently, the user must examine the spectra to determine if there are any contaminates, such as beryllium present. The HH-LIBS provided access to the measured intensity vs. pixel number, but to be useful for contamination detection the wavelength needs to be known.

Some elements were tested to determine the data quality of the HH-LIBS, the useful detection range for contaminant detection in nuclear environments and to convert pixel number to wavelength. To do this a comparison of the raw data obtained by the HH-LIBS was made, to a large desktop-based LIBS- 8 instrument, with a higher quality laser and spectrometer setup (section 2.1.3).
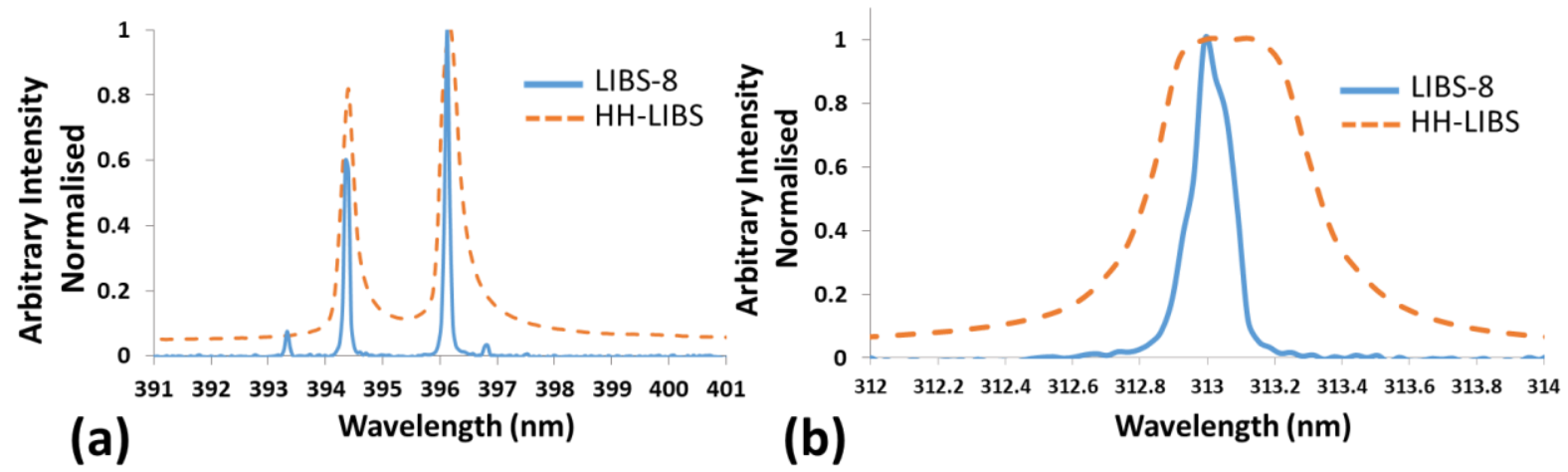

Figure 8. Emission line example of (a) aluminium (b) beryllium measured by the applied photonics LIBS 8 and the Hitachi High-tech LIBS instrument.

To estimate the wavelength range, spectra (of aluminium, beryllium, boron, silicon and zinc) were calibrated against known spectra measured by the LIBS-8. The spectral range was approximately $237-516 \mathrm{~nm}$. A simple comparison of the emission peaks at 394.4 and 396.15 $\mathrm{nm}$ of aluminium (Figure 8(a)), gave a FWHM fit of $0.3 \mathrm{~nm}$ for $394.4 \mathrm{~nm}\left(3 \mathrm{p}^{2} \mathrm{P}^{\circ}-4 \mathrm{~s}^{2} \mathrm{~S}\right)$ and $0.4 \mathrm{~nm}$ for $396.15 \mathrm{~nm}\left(3 \mathrm{p}^{2} \mathrm{P}^{\circ}-4 \mathrm{~s}^{2} \mathrm{~S}\right)$, vs. a FWHM of $0.09 \mathrm{~nm}$ for both peaks measured on the LIBS-8 instrument (which has a resolution of $\sim 0.07 \mathrm{~nm}$ in this range, measured using a $\mathrm{Hg}$ lamp).

The emission line peaks of the aluminium slightly overlap on the HH-LIBS (Figure 8 (a)), but are well separated on the LIBS-8. For reliable, multi-application and multi-element contamination detection, overlapping emission lines would be problematic and add complexity to analysis that may be hard to overcome.

Emission lines exhibit broadening in part, due to plasma temperature [68], and evolve as the plasma cools [69]. As the laser power density, spectrometer delay and integration times are unknown (and are not adjustable) for the HH-LIBS, the differences in FWHM measured between instruments may not be due to the resolution of the spectrometer, but the plasma conditions during the measured period. It is likely that the spectrometer had a higher resolution than $0.3 \mathrm{~nm}$, as a compact Czerny-Turner spectrometer (with 4096 pixels, slit size: $10 \mu \mathrm{m}$, grating: 900 lines $/ \mathrm{mm}$ ) could cover a spectral range of $\sim 300 \mathrm{~nm}$, at a resolution of $\sim 0.25 \mathrm{~nm}$. 
Consequently, to improve the spectral resolution, optimisation, or control over the spectrometer, timings and laser power, triggering times and jitter may be advantageous.

\subsubsection{Contamination detection}

Beryllium was straightforward to detect with both LIBS instruments and has strong peaks at $313.04 \mathrm{~nm}\left(2 \mathrm{~s}^{2} \mathrm{~S}-2 \mathrm{p}{ }^{2} \mathrm{P}^{\circ}\right)$ and $313.11 \mathrm{~nm}\left(2 \mathrm{~s}^{2} \mathrm{~S}-2 \mathrm{p}{ }^{2} \mathrm{P}^{\circ}\right)$, which were seen as a single peak (Figure 8(b)) on both instruments, due to spectrometer resolution. The LIBS-8 fitted a FWHM of $0.15 \mathrm{~nm}$ to the $313.04 / 313.11 \mathrm{~nm}$ peak, while the HH-LIBS fitted a FWHM of $\sim 0.45 \mathrm{~nm}$. Other beryllium peaks with a good signal, detected by the HH-LIBS and verified by the LIBS8 , include $249.46 / 249.47 \mathrm{~nm}\left(2 \mathrm{p}{ }^{3} \mathrm{P}-3 \mathrm{~d}{ }^{3} \mathrm{D}\right), 332.1 / 332.11 / 332.13 \mathrm{~nm}\left(2 \mathrm{p}{ }^{3} \mathrm{P}^{\circ}-3 \mathrm{~s}{ }^{3} \mathrm{~S}\right)$ and $327.46 / 327.47 \mathrm{~nm}\left(3 \mathrm{~s}^{2} \mathrm{~S}-4 \mathrm{p}^{2} \mathrm{P}^{\circ}\right)$. Despite the low laser power, resolution and spectral range of the compact HH-LIBS, these beryllium peaks would be adequate for a good range of beryllium identification applications.

A spectral range of $~ 237-516 \mathrm{~nm}$ covers intense peaks of most elements of interest, with plutonium, uranium, caesium, strontium and beryllium, having peaks within this range. Yet, the strongest, or most desirable peak of an element of interest, may be outside this narrow, yet useful (237-516 nm) spectral range. Conflicting peaks with other elements, will occur for many samples and additional peaks usually used to confirm the first-choice peaks are unlikely to be available, without an extended wavelength range. For example, the spectrum for caesium exhibits the $455.53 \mathrm{~nm}$ and $459.32 \mathrm{~nm}$ emission lines but does not possess the widely used $852.1 \mathrm{~nm}$ or $894.35 \mathrm{~nm}$ peak for additional confirmation. In the study by Lang et al. of caesium contamination using a LIBS-8 instrument, the lines at $455.53 \mathrm{~nm}$ and $459.32 \mathrm{~nm}$ had interference from chromium and iron lines from the stainless steel matrix [42] Some elements are unlikely to be detectable within this range, such as sulphur, where a simple LIBS setup is most likely to detect emission lines at 921.3, 922.8 and $923.8 \mathrm{~nm}$ (a discussion on additional sulphur lines is given in reference [70]). For nuclear environments where purging of the optical path would be problematic (where purging is required to go below $200 \mathrm{~nm}$ and a vacuum below $175 \mathrm{~nm}$ ), an instrument with a wavelength range of $\sim 200-950 \mathrm{~nm}$ would provide a comprehensive wavelength range for LIBS analysis.

For samples that contain many elements (or elements like iron, with many spectral lines), the relatively low resolution of the HH-LIBS, increases the probability of overlapping spectral lines, making positive identification of contamination difficult. A LIBS unit with higher resolution and a larger wavelength range is feasible in a variety of compact forms, including handheld of similar size. Current handheld units with a larger wavelength range, or higher (advertised) resolution are significantly more expensive, but would increase certainty and the range of contaminants that could be detected, along with providing improved classification of materials, with the caveat that hardware and software quality would have to be maintained (or improved).

For deployment on different robotic platforms, the components of a compact handheld LIBS system can be reconfigured to provide a more suitable geometry. This would increase the number of possible deployment environments and number of robotic platforms that could carry a LIBS unit. Compact more powerful pulsed lasers are available (compared with the laser used in the HH-LIBS) and would allow measurements to be made from a greater distance, decreasing exposure to gamma radiation and reducing contamination concerns. 


\subsubsection{Contact Raman deployment}

525

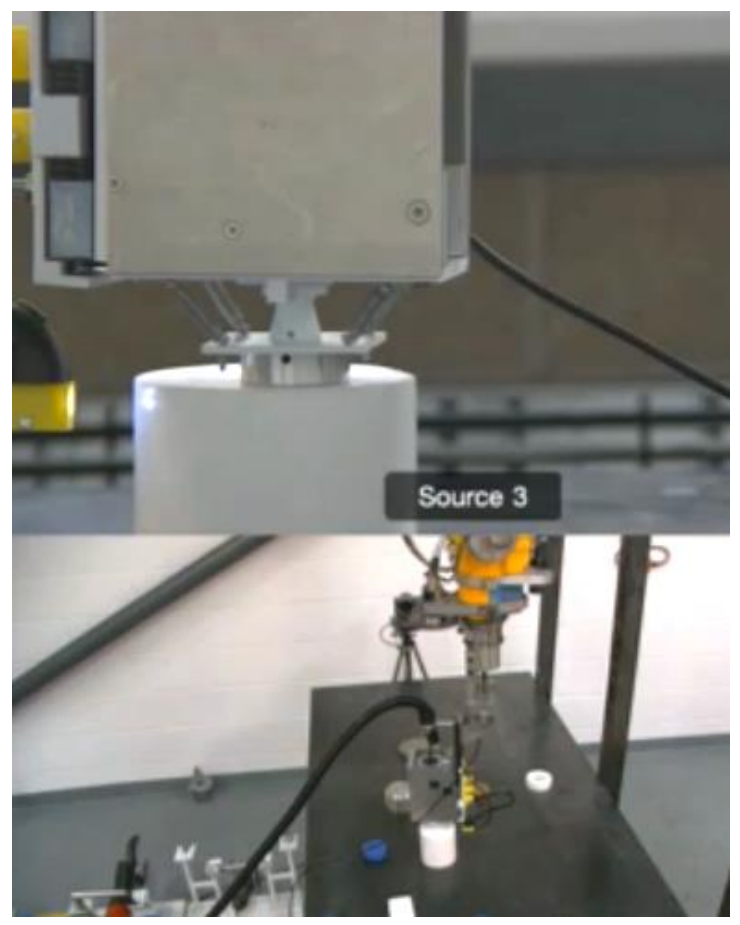

Figure 9. Robotic arm mounted contact Raman Probe, within simulated active hot cell on the M3000 robotic arm, taking a measurement on the sorting table. View from CCTV cameras 3 and 4 in the control room.

The robotic arm mounted Raman contact probe, shown operating in Figure 9, within the simulated hot cell, was effective at measuring solid samples whilst being operated from the control room. Samples at multiple orientations, from vertical to horizontal were tested and all measurements were successful. The mount was simpler in operational steps than the contact LIBS equivalent, which required greater operator experience to align prior to a measurement.

To mate the Raman probe with a solid sample, the probe was gently pushed against the samples and the probe self-aligned and sealed to form a dark environment, ready for measurements to begin. To self-align reliably, the samples had to be around $2 \mathrm{~cm}$ in diameter or greater. The contact Raman mount had multiple cushioning points, so the probe would recoil when pushed against the sample too hard, this feature allowed the operator of the M3000 to make rapid sample mating. A good dark background was obtained with a rough poured concrete floor using no gasket, if roughness was an issue, a modified sampling cap with a gasket seal was available but was not required for this study. Two approaches were used to obtain spectra from powdered and small granule samples. For powdered and small granule samples with a mound like geometry, the aperture of the Raman sampling cap was pushed gently against the sample until a dark background could be measured, where full alignment was unnecessary. For a powdered and small granule geometry pile that was flat on a firm supporting substrate (e.g. the floor of the simulated active hot cell), the sample was measured using the same methodology as the solid samples.

In the well-lit hot cell, variable ambient light penetrated through most samples and interfered with the weak Raman signal. This was mitigated against by measuring a dark background 
signal. For samples that were less transparent to light, the spectrometer signal for the dark measurements would drop to the expected level of a completely dark environment, indicating that the seal between the sampling cap of the probe and the sample worked well. As most decommissioning environments tend to be dark, interference from ambient light would be

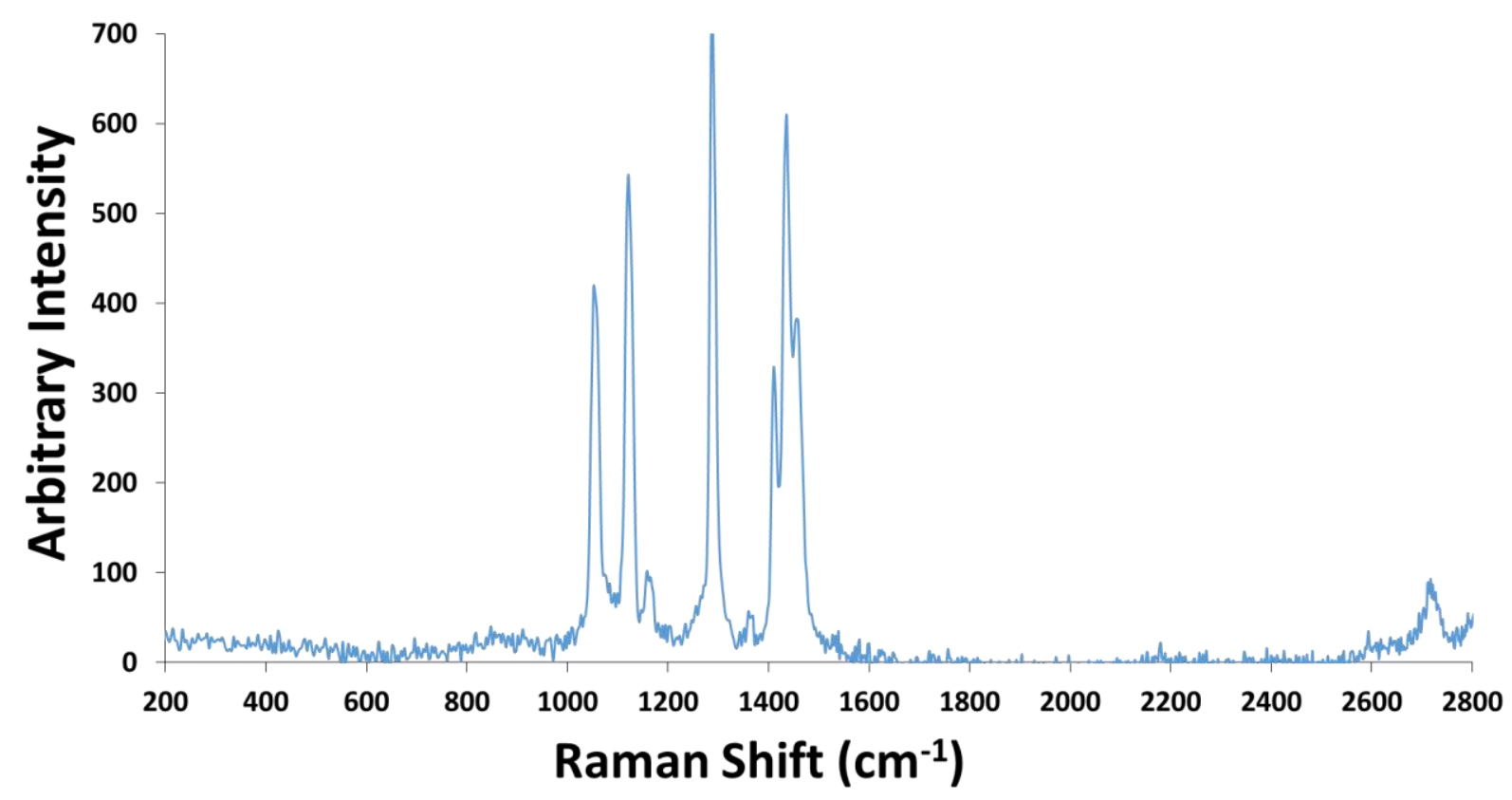

557 Figure 10. Contact probe Raman spectra of HDPE measured over 16 metres of optical fibres.

558 A measurement of high-density polyethylene (HDPE) is shown in Figure 10, as measured by 559 the contact probe. The spectral data gathered in the simulated active hot cell with daylight and 560 all lights on and with the signal transmitted over the 16 meters of optical fibre umbilical was 561 good for identification purposes and was sent back to the control room and added to a database, 562 along with a photo of the sample measured.

563 Materials (with at least 5 samples for each material) of PTFE, LDPE, PET, PP, PEEK, 564 polystyrene and samples of an unknown coating on metal, labelled rubberised coating were 565 placed on the sorting table for characterisation (by Raman spectroscopy). The unknown coating 566 on metal, labelled "rubberised coating" was identified as high-density polyethylene (HDPE) 567 via the Raman spectra, with an elevated degree of fluorescence due to a colour/dye additive. 


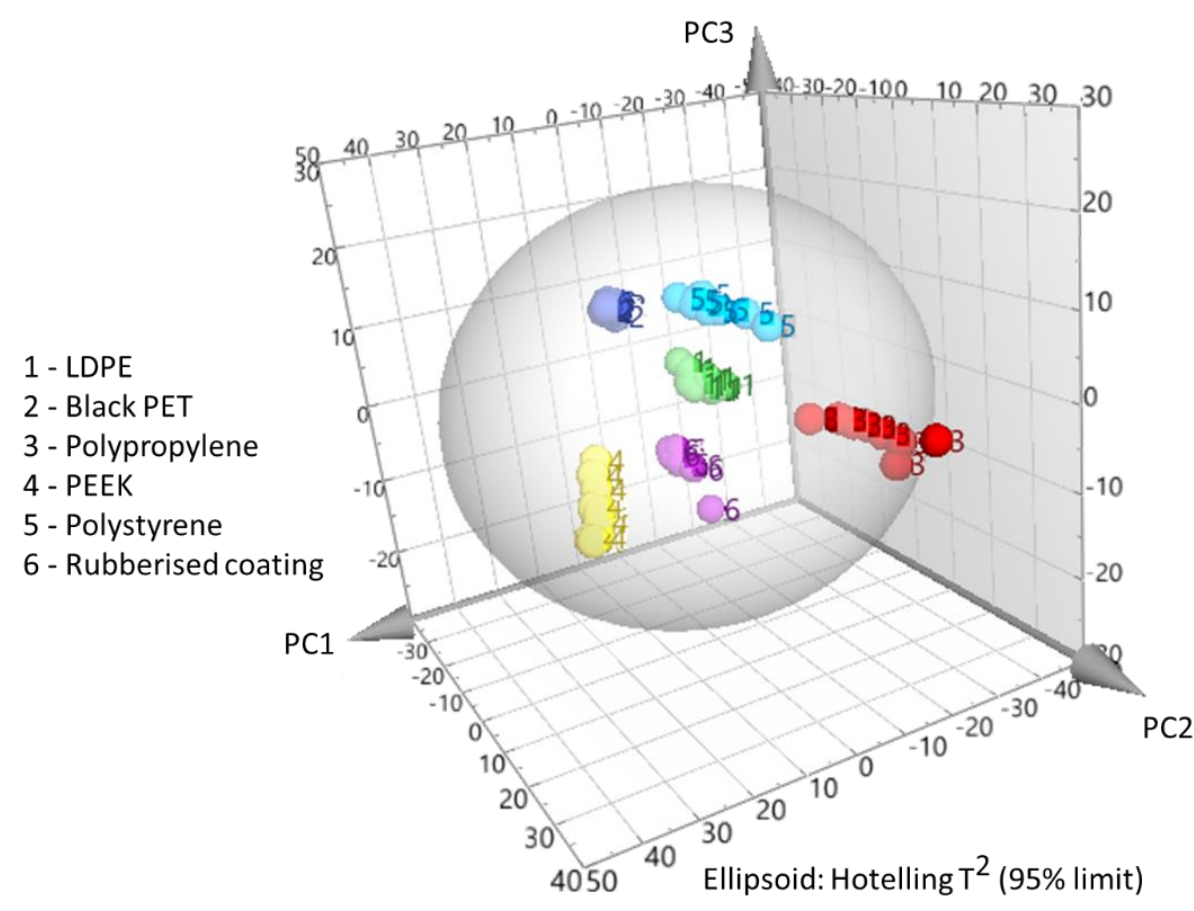

Figure 11. PCA analysis of Raman spectra measured by the Raman probe setup, shows discrimination between all the different samples, made up of six different materials. The first three principal component (PC) explained $65 \%$ of the variance in the Raman data.

After each Raman measurement the spectra from each sample were sent back to the control room where they were processed and separated by principal component analysis (PCA), as shown in Figure 11. With PCA analysis each sample was clearly separated based on its material type using the first 3 principal components.

\section{6}

\subsubsection{Stand-off Raman spectroscopy}
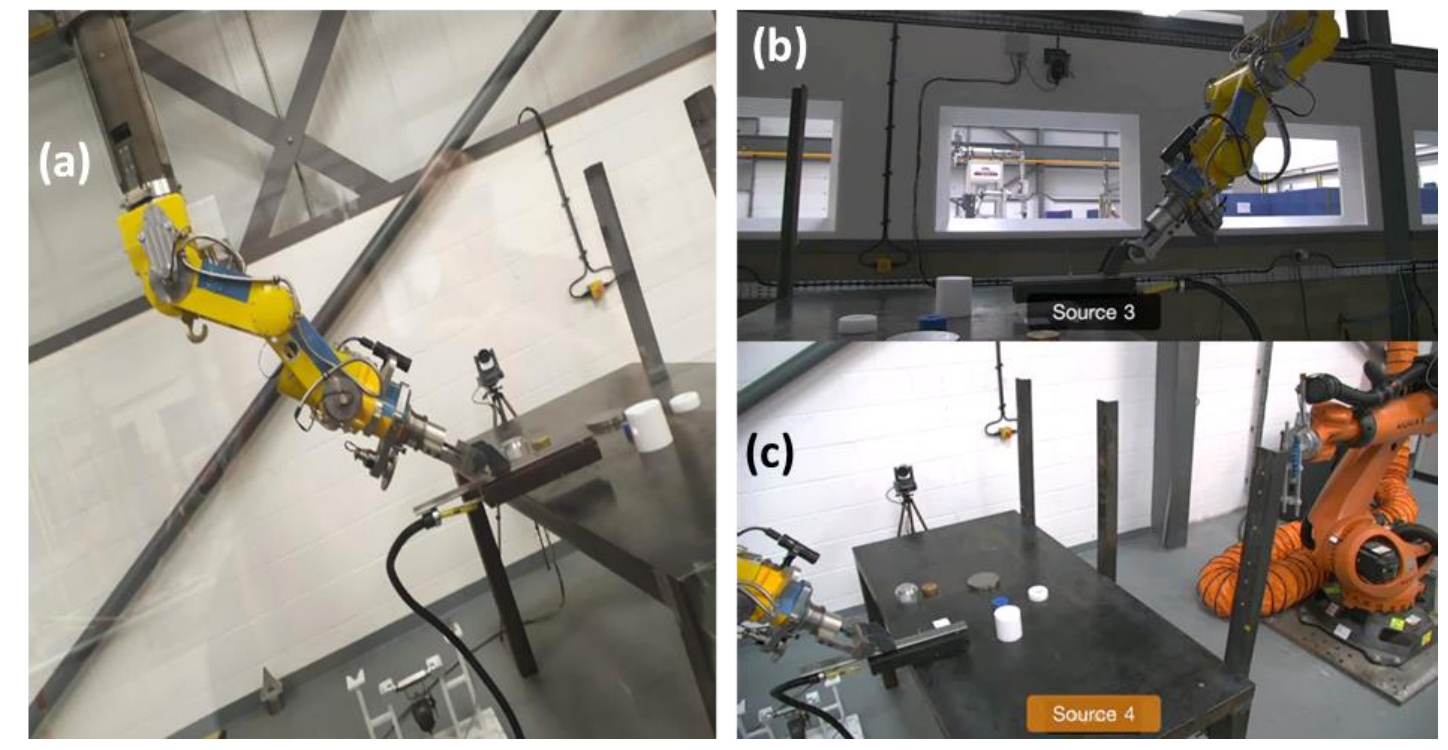

578 Figure 12. Stand-off Raman probe (a) Making a measure measurements in the simulated active hot cell window view, (b) \& (c) view from control room during the day time. 
The stand-off Raman probe (Figure 12) achieved measurements over many metres under controlled lighting conditions. Compared to a measurement done at a distance of $30 \mathrm{~cm}$ away from the sample, at a distance of 1 metre the Raman to background signal decreased to $70 \%$ and at a distance of 4 metres the Raman to background signal had decreased to $\sim 30 \%$ and was still able to obtain good spectra. After laser safety considerations were enacted for open beam work (enacting controls against the collimated laser beam interacting with personnel, for example through a viewing window), the measurement was a simple point and shoot. The simulated hot cell could not be shielded from daylight emanating from multiple skylights at the PaR facility, so lighting was not controllable in the same manner as most real hot cells, the influence of the variable daylight could not be removed from the spectra by background subtraction. To improve the Raman signal the probe was moved to within $30 \mathrm{~cm}$ of the sample and the spectra could be clearly identified as PTFE, with all expected peaks clearly discernible. However, the degraded Raman signal could not separate LDPE, PET, PP, PEEK, polystyrene and the HDPE coating cleanly and reliably, as some of the samples have a much weaker Raman signal than PTFE. In ambient darkness, measurements consistent with the contact Raman probe were obtained, at an arbitrary distance of 1 metre. The test samples were comparable to the contact probe tests and separation of the samples was possible in the same manner as demonstrated by the contact probe (shown in Figure 11).

As the stand-off Raman probe is collimated and not tightly focused, the power density was not very high and can be increased further with a more powerful laser without sample damage. While the laser power density at the sample interface, is below the materials damage threshold, an increase in laser power density will (typically) increase the Raman signal. Therefore, a more powerful laser would help overcome some of interference from ambient light. The advantage of the $785 \mathrm{~nm}$ excitation laser is the suppression of fluorescence encountered in many samples that can overwhelm the Raman signal. If fluorescence is not an issue, a shorter excitation wavelength increases the Raman signal, since Raman scattering intensity is proportional to $\lambda^{-4}$ [71]. For brighter environments that can be problematic for stand-off Raman and for samples with a weak Raman signal (and little fluorescence), a shorter wavelength laser (e.g. $532 \mathrm{~nm}$ ) would be advantageous. Consequently, an extra Raman probe/tool, operating at a shorter wavelength would increase the versatility of technique.

\subsection{Data visualisation}

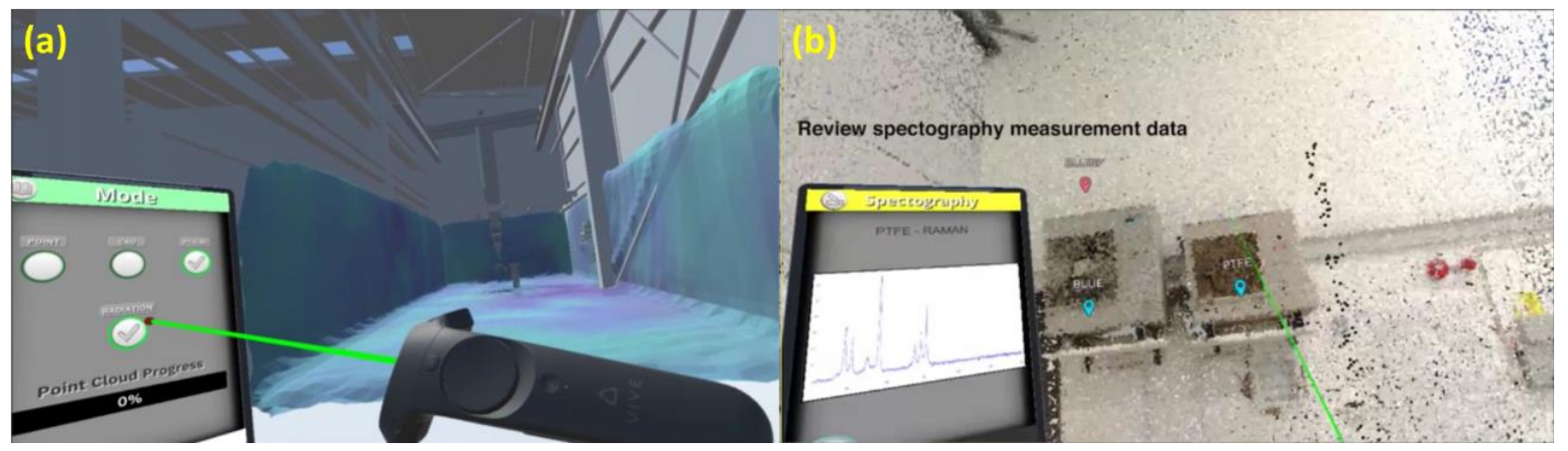

Figure 13. User navigates virtual environment of the hot cell that incorporates the measured characterisation data (a) user selects data types to overlay on the virtual tablet and pointer, (b) user selects LIBS and Raman information of objects, tagged as points of interest in the virtual environment, with photogrammetry overlaid, user selection of Raman spectra of PTFE is shown on the virtual tablet. 
To demonstrate how the information collected could be visualised and accessed more intuitively, the data were mapped into a virtual environment, where the user could navigate around the facility. As shown in Figure 13, the virtual environment allowed users to walk around and identify objects and areas of interest and look at what was known about those samples and objects through characterisation. In Figure 13, the user is shown accessing Raman data associated with an object, within the simulated hot cell and can see the conditions they existed in when the measurements were taken. This visualisation allows rapid comprehension of complex characterisation data in the context of the environment. So informed decision making can be made with less ambiguity.

To simplify the ability to interrogate collected data, including by 3D visualisation, development and testing of a spatial database management system (SDMBS) is in progress [54]. The database can store vast amounts of characterisation data including, 2D, 3D and 4D (timeseries), point cloud data, geographical information system data and building information management data from nuclear sites across the UK. When integrated with Data Quality Objectives (DQO) [72, 73] stored data can be used to develop statistically-based strategies for the collection of new characterisation data.

\subsection{Conclusion}

The feasibility of deploying a commercial off the shelf (COTS) Raman and LIBS remote characterisation system on a robotic arm, as part of the process of decommisiong a generic nuclear industry hot cell, has been examined and successfully demonstrated. This was achieved by the creation of mounts and probes that a robotic arm could pick up, in a generic hot cell environment and use to distinguish materials that would allow correct waste streams to be identified. The developed probes and mounts were operated from an isolated control room, where good sample alignment was demonstrated for each technique.

It was shown that low cost COTS LIBS, could make quick metal grade classification whilst attached to the robotic arm and limitations were revealed and discussed for contamination detection, using aluminum and beryllium as examples. To improve future deployment of LIBS, an increase in spectral resolution and wavelength range would improve confidence in the analysis of contamination.

For Raman spectroscopy, a contact and a stand-off probe were developed. The design was modular, with the laser and spectrometer outside of the simulated active hot cell and the probes coupled fibre-optically into the cell. No operational issues were encountered with the Raman contact probe, the data that were collected were high quality and samples tested were automatically grouped based on the material type (via PCA).

As Raman measurements can take a long time to acquire (many minutes for Raman spectroscopy vs. seconds for HH-LIBS), a stand-off probe that could operate further away from a source was developed and tested. In the simulated active hot cell, the stand-off probe operated well from a distance, but needed low and controlled ambient light conditions to be able to acquire equivalent data to that of the contact probe. To improve future deployments of standoff Raman, an additional probe operating at a shorter wavelength could be added to the available tool-kit for use in brighter environments and for samples with weaker signals. 
To demonstrate how the data held on a decommissioning environment can be accessed in a more intuitive way, an example of the characterisation data mapped into the virtual environment of the hot cell was shown.

In general, the characterisation technology demonstrated can be adapted to multiple platforms and environments, such as standalone autonomous robots and access ports. For both techniques, increased radiation hardening should be implemented. The robotic mounts developed can be adapted for other techniques and probes of similar formats. The mount for HH-LIBS can be adapted to other hand held instruments available that operate in a similar manner, such as, X-ray fluorescence (XRF) [74], hyperspectral imaging (HSI) and Fouriertransform infrared spectroscopy (FTIR).

In the future, a more informed and guided measurement approach should be implemented to minimise measurement time, whilst ensuring a representative picture of a sample is made. Decisions on the locations to measure should be guided by DQO [72, 73], using completed measurements (stored in a database [54]) and real time characterisation measurements from complementary techniques. Decisions on the settings used, number of measurements and the locations to collect data from, should move towards a more automated approach, along with determination of acceptable tolerances on decision errors. To move towards a more automated analysis of LIBS and Raman, a library of spectral data and corresponding standards (including mixed wastes), is being constructed. A more automated characterisation set-up would simplify future deployment on teleoperable and autonomous robotic platforms.

\subsection{Acknowledgements}

This research was supported by UK Research and Innovation (UKRI), via the EPSRC TORONE project grant number EP/P018505/1 (www.TORONE-project.com). Partial funding was also received from Nuvia UK as part of an Innovate UK grant. N.Smith was funded through a Royal Society Industry Fellowship and NNL Core Science Group Decontamination IR\&D Theme.

Deployment was conducted at and supported by, PaR Systems, Remote Handling and Service team, European Centre of Excellence, Lillyhall, Cumbria.

\subsection{References}

[1] M.I. Ojovan, W.E. Lee, Chapter 12 - Management and Characterisation of Radioactive Wastes, in: M.I. Ojovan, W.E. Lee (Eds.) An Introduction to Nuclear Waste Immobilisation, Elsevier, Oxford, 2005, pp. 125-134.

[2] O. Pinet, J.L. Dussossoy, C. David, C. Fillet, Glass matrices for immobilizing nuclear waste containing molybdenum and phosphorus, Journal of Nuclear Materials, 377 (2008) 307-312. [3] Office for Nuclear Regulation, The management of higher activity radioactive waste on nuclear licensed sites in, Office for Nuclear Regulation, 2015.

[4] C.M. Jantzen, M.I. Ojovan, On Selection of Matrix (Wasteform) Material for Higher Activity Nuclear Waste Immobilization (Review), Russian Journal of Inorganic Chemistry, 64 (2019) 16111624.

[5] S.V. Stefanovsky, S.V. Yudintsev, R. Gieré, G.R. Lumpkin, Nuclear waste forms, Geological Society, London, Special Publications, 236 (2004) 37-63.

[6] A. Fernandez-Jimenez, D.E. Macphee, E.E. Lachowski, A. Palomo, Immobilization of cesium in alkaline activated fly ash matrix, Journal of Nuclear Materials, 346 (2005) 185-193. 
[7] R. Bogue, Robots in the nuclear industry: a review of technologies and applications, Industrial Robot: An International Journal, 38 (2011) 113-118.

[8] T. White, N. Hewer, B.L. Luk, J. Hazel, The design and operational performance of a climbing robot used for weld inspection in hazardous environments, in: Proceedings of the 1998 IEEE International Conference on Control Applications (Cat. No.98CH36104), 1998, pp. 451-455 vol.451. [9] K.A. Manocha, N. Pernalete, R.V. Dubey, Variable position mapping based assistance in teleoperation for nuclear cleanup, in: Proceedings 2001 ICRA. IEEE International Conference on Robotics and Automation (Cat. No.01CH37164), 2001, pp. 374-379 vol.371.

[10] C.J. Lissenden, S. Choi, H. Cho, A. Motta, K. Hartig, X. Xiao, S. Le Berre, S. Brennan, K. Reichard, R. Leary, B. McNelly, I. Jovanovic, Toward Robotic Inspection of Dry Storage Casks for Spent Nuclear Fuel, Journal of Pressure Vessel Technology, 139 (2017).

[11] D. Connor, P.G. Martin, T.B. Scott, Airborne radiation mapping: overview and application of current and future aerial systems, International Journal of Remote Sensing, 37 (2016) 5953-5987. [12] D.T. Connor, P.G. Martin, N.T. Smith, L. Payne, C. Hutson, O.D. Payton, Y. Yamashiki, T.B. Scott, Application of airborne photogrammetry for the visualisation and assessment of contamination migration arising from a Fukushima waste storage facility, Environmental Pollution, 234 (2018) 610619.

[13] P.G. Martin, S. Kwong, N.T. Smith, Y. Yamashiki, O.D. Payton, F.S. Russell-Pavier, J.S. Fardoulis, D.A. Richards, T.B. Scott, 3D unmanned aerial vehicle radiation mapping for assessing contaminant distribution and mobility, International Journal of Applied Earth Observation and Geoinformation, 52 (2016) 12-19.

[14] I. Tsitsimpelis, C.J. Taylor, B. Lennox, M.J. Joyce, A review of ground-based robotic systems for the characterization of nuclear environments, Progress in Nuclear Energy, 111 (2019) 109-124.

[15] C. Lee, H.R. Kim, Optimizing UAV-based radiation sensor systems for aerial surveys, Journal of Environmental Radioactivity, 204 (2019) 76-85.

[16] M. Nancekievill, A.R. Jones, M.J. Joyce, B. Lennox, S. Watson, J. Katakura, K. Okumura, S. Kamada, M. Katoh, K. Nishimura, A Remote-operated System to Map Radiation Dose in the Fukushima Daiichi Primary Containment Vessel, EPJ Web Conf., 170 (2018) 06004.

[17] K. Jeong, D. Lee, K. Lee, H. Lim, A qualitative identification and analysis of hazards, risks and operating procedures for a decommissioning safety assessment of a nuclear research reactor, Annals of Nuclear Energy, 35 (2008) 1954-1962.

[18] K. Nagatani, S. Kiribayashi, Y. Okada, K. Otake, K. Yoshida, S. Tadokoro, T. Nishimura, T. Yoshida, E. Koyanagi, M. Fukushima, S. Kawatsuma, Emergency response to the nuclear accident at the Fukushima Daiichi Nuclear Power Plants using mobile rescue robots, Journal of Field Robotics, 30 (2013) 44-63.

[19] R. Sharp, M. Decréton, Radiation tolerance of components and materials in nuclear robot applications, Reliability Engineering \& System Safety, 53 (1996) 291-299.

[20] W. Wang, K. Yuan, Teleoperated manipulator for leak detection of sealed radioactive sources, in: IEEE International Conference on Robotics and Automation, 2004. Proceedings. ICRA '04. 2004, 2004, pp. 1682-1687 Vol.1682.

[21] L. Briones, P. Bustamante, M.A. Serna, Wall-climbing robot for inspection in nuclear power plants, in: Proceedings of the 1994 IEEE International Conference on Robotics and Automation, 1994, pp. 1409-1414 vol.1402.

[22] C. Tsabaris, D. Ballas, On line gamma-ray spectrometry at open sea, Applied Radiation and Isotopes, 62 (2005) 83-89.

[23] S. Okada, K. Ishizawa, Y. Murai, Development of internal investigation device for primary containment vessel Shape changing robot 'PMORPH', Denki Hyoron, 102 (2017) 27-31.

[24] R. Buckingham, A. Graham, Nuclear snake-arm robots, Industrial Robot: An International Journal, 39 (2012) 6-11. 
[25] R. Redus, M. Squillante, J. Gordon, G. Knoll, D. Wehe, A combined video and gamma ray imaging system for robots in nuclear environments, Nuclear Instruments and Methods in Physics Research Section A: Accelerators, Spectrometers, Detectors and Associated Equipment, 353 (1994) 324-327. [26] B.L. Luk, K.P. Liu, A.A. Collie, D.S. Cooke, S. Chen, Tele-operated climbing and mobile service robots for remote inspection and maintenance in nuclear industry, Industrial Robot: An International Journal, 33 (2006) 194-204.

[27] G.A. Fairhall, J.D. Palmer, The encapsulation of Magnox Swarf in cement in the United Kingdom, Cement and Concrete Research, 22 (1992) 293-298.

[28] M. Laraia, 7 - Decommissioning of nuclear facilities and environmental remediation: generation and management of radioactive and other wastes, in: M.I. Ojovan (Ed.) Handbook of Advanced Radioactive Waste Conditioning Technologies, Woodhead Publishing, 2011, pp. 173-204. [29] M. Hayes, I.H. Godfrey, Development of the Use of Alternative Cements for the Treatment of Intermediate Level Waste, ; WM Symposia, 1628 E. Southern Avenue, Suite 9 - 332, Tempe, AZ 85282 (United States), 2007.

[30] I.D. Kempsell, M.J. Wakem, M. Fairclough, J.M. Ingram, HYDROGEN EXPLOSIONS-AN EXAMPLE OF HAZARD AVOIDANCE AND CONTROL, in, 2001.

[31] IAEA, Record Keeping for the Decommissioning of Nuclear Facilities: Guidelines and Experience, in: Technical Reports Series No. 4II, 2002.

[32] A. Kahraman, Retrieval, Restoration and Maintenance of Old Radioactive Waste Inventory Records, in: Division of Nuclear Fuel Cycle and Waste Technology (Ed.), IAEA, 2007.

[33] J.P. Caire, S. Cullie, F. Dalard, J.M. Fulconis, H. Delagrange, AISI 304 L stainless steel decontamination by a corrosion process using cerium IV regenerated by ozone Part II: Process optimization, Journal of Applied Electrochemistry, 33 (2003) 709-715.

[34] M.E. Pick, The nature of PWR stainless steel and Inconel oxides in relation to decontamination in permanganate based (NP and AP) processes, British Nuclear Energy Society, United Kingdom, 1983. [35] J. Torok, An oxidizing pretreatment for the decontamination of austenitic alloys by CAN-DECON, in: Decontamination of nuclear facilities, Canada, 1982, pp. 633.

[36] J.F.C. De Lucia, J.L. Gottfried, C.A. Munson, A.W. Miziolek, Multivariate analysis of standoff laser-induced breakdown spectroscopy spectra for classification of explosive-containing residues, Appl. Opt., 47 (2008) G112-G121.

[37] J.L. Gottfried, F.C. De Lucia, C.A. Munson, A.W. Miziolek, Laser-induced breakdown spectroscopy for detection of explosives residues: a review of recent advances, challenges, and future prospects, Analytical and Bioanalytical Chemistry, 395 (2009) 283-300.

[38] J. Moros, J.A. Lorenzo, J.J. Laserna, Standoff detection of explosives: Critical comparison for ensuing options on Raman Spectroscopy-LIBS sensor fusion, Analytical and bioanalytical chemistry, 400 (2011) 3353-3365.

[39] J.P.O. Horsfall, D. Trivedi, N.T. Smith, P.A. Martin, P. Coffey, S. Tournier, A. Banford, L. Li, D. Whitehead, A. Lang, G.T.W. Law, A new analysis workflow for discrimination of nuclear grade graphite using laser-induced breakdown spectroscopy, Journal of Environmental Radioactivity, 199200 (2019) 45-57.

[40] M. Hoehse, A. Paul, I. Gornushkin, U. Panne, Multivariate classification of pigments and inks using combined Raman spectroscopy and LIBS, Analytical and Bioanalytical Chemistry, 402 (2012) 1443-1450.

[41] R.C. Wiens, S. Maurice, F. Rull Perez, The SuperCam remote sensing instrument suite for the Mars 2020 rover mission: A preview, Spectroscopy, 32 (2017).

[42] A. Lang, D. Engelberg, N.T. Smith, D. Trivedi, O. Horsfall, A. Banford, P.A. Martin, P. Coffey, W.R. Bower, C. Walther, M. Weiß, H. Bosco, A. Jenkins, G.T.W. Law, Analysis of contaminated nuclear plant steel by laser-induced breakdown spectroscopy, Journal of Hazardous Materials, 345 (2018) 114-122. 
[43] A.I. Whitehouse, J. Young, I.M. Botheroyd, S. Lawson, C.P. Evans, J. Wright, Remote material analysis of nuclear power station steam generator tubes by laser-induced breakdown spectroscopy, Spectrochimica Acta Part B: Atomic Spectroscopy, 56 (2001) 821-830.

[44] A.I. Whitehouse, Laser-induced breakdown spectroscopy and its application to the remote characterisation of hazardous materials, Spectroscopy Europe, 18 (2006) 14-21.

[45] Z.J. Diggins, N. Mahadevan, D. Herbison, G. Karsai, E. Barth, R.A. Reed, R.D. Schrimpf, R.A. Weller, M.L. Alles, A. Witulski, Range-Finding Sensor Degradation in Gamma Radiation Environments, IEEE Sensors Journal, 15 (2015) 1864-1871.

[46] P.E. Dodd, M.R. Shaneyfelt, J.R. Schwank, J.A. Felix, Current and Future Challenges in Radiation Effects on CMOS Electronics, IEEE Transactions on Nuclear Science, 57 (2010) 1747-1763.

[47] A. Calderón, E. Calvo, C.F. Figueroa, C. Martínez-Rivero, F. Matorras, T. Rodrigo, M. Sobrón, I. Vila, A.L. Virto, P. Arce, J.M. Barcala, A. Ferrando, M.I. Josa, J.M. Luque, A. Molinero, J. Navarrete, J.C. Oller, C. Yuste, Effects of the gamma-ray irradiation on the optical absorption of pure silica core single-mode fibres in the visible and NIR range, Nuclear Instruments and Methods in Physics Research Section A: Accelerators, Spectrometers, Detectors and Associated Equipment, 538 (2005) 810-813.

[48] E. Regnier, I. Flammer, S. Girard, F. Gooijer, F. Achten, G. Kuyt, Low-Dose Radiation-Induced Attenuation at InfraRed Wavelengths for P-Doped, Ge-Doped and Pure Silica-Core Optical Fibres, IEEE Transactions on Nuclear Science, 54 (2007) 1115-1119.

[49] S. Baccaro, A. Cemmi, I. Di Sarcina, F. Menchini, Gamma Rays Effects on the Optical Properties of Cerium-Doped Glasses, International Journal of Applied Glass Science, 6 (2015) 295-301. [50] S.M. Javed Akhtar, M. Ashraf, S.H. Khan, A study of neutron and gamma radiation effects on transmission of various types of glasses, optical coatings, cemented optics and fiber, Optical Materials, 29 (2007) 1595-1603.

[51] J. Norris, S. Norman, M. Tribble, Mechanical degradation of polymer-coated glass optical fibres under y irradiation, SPIE, 1990.

[52] Z. Wang, Y. Ma, J. Liu, Y. Xue, B. He, Z. Yao, S. Huang, M. Liu, J. Sheng, Degradation and annealing studies on gamma rays irradiated COTS PPD CISs at different dose rates, Nuclear Instruments and Methods in Physics Research Section A: Accelerators, Spectrometers, Detectors and Associated Equipment, 820 (2016) 89-94.

[53] NDA, Guide to Technology Readiness Levels for the NDA Estate and its Supply Chain in: N.D. Authority (Ed.), UK, 2014.

[54] I.T. Andrew West, Paul Coffey, Michael Aspinall, Nick Smith, Malcolm J. Joyce, Barry Lennox, Philip A. Martin, TORONE: Total Characterisation by Remote Observation of Nuclear Environments 20591, in: WM2020, Phoenix, Arizona, USA, 2020.

[55] A.G. Harmsen, M.D. Hoover, F.A. Seiler, Health risk implications of using beryllium in fusion reactors, Journal of Nuclear Materials, 122 (1984) 821-826.

[56] A.T. T, Beryllium - A Unique Material in Nuclear Applications, in, United States, 2004, pp. v. [57] D. Torcy, C. Spencer Pitcher, A. Dammann, E. Gouhier, D. Canas, Provisions for ITER decommissioning - 000090, in: DEM 2018: International conference on dismantling challenges: industrial reality, prospects and feedback experience, France, 2018.

[58] J.S. Johnson, K. Foote, M. McClean, G. Cogbill, Beryllium Exposure Control Program at the Cardiff Atomic Weapons Establishment in the United Kingdom, Applied Occupational and Environmental Hygiene, 16 (2001) 619-630.

[59] H.M. Sackett, L.A. Maier, L.J. Silveira, M.M. Mroz, L.G. Ogden, J.R. Murphy, L.S. Newman, Beryllium Medical Surveillance at a Former Nuclear Weapons Facility During Cleanup Operations, Journal of Occupational and Environmental Medicine, 46 (2004) 953-961.

[60] J. El Haddad, L. Canioni, B. Bousquet, Good practices in LIBS analysis: Review and advices, Spectrochimica Acta - Part B Atomic Spectroscopy, 101 (2014) 171-182. 
[61] T.-L. Zhang, S. Wu, H.-S. Tang, K. Wang, Y.-X. Duan, H. Li, Progress of Chemometrics in Laserinduced Breakdown Spectroscopy Analysis, Chinese Journal of Analytical Chemistry, 43 (2015) 939948.

[62] V.C. Costa, D.V. Babos, J.P. Castro, D.F. Andrade, R.R. Gamela, R.C. Machado, M.A. Sperança, Spectroscopy: A Critical Review of Advances and Challenges, Journal of the Brazilian Chemical Society, 31 (2020) 2439-2451. [63] K.O. A. Kramida, Y. Ralchenko, Nist LIBS Database, in, National Institute of Standards and Tehonology.

[64] PLASUS, SpecLine, in, PLASUS GmbH.

858 [65] Michael M. CarrabbaR. David Rauh, Apparatus for measuring Raman spectra over optical fibers, 859 in, Eic Laboratories Inc, US, 1992

860 [66] G.J. Newton, M.D. Hoover, E.B. Barr, B.A. Wong, P.D. Ritter, Collection and Characterization of Aerosols from Metal Cutting Techniques Typically Used in Decommissioning Nuclear Facilities, American Industrial Hygiene Association Journal, 48 (1987) 922-932.

[67] B. Lambrecht, J. Dixon, J.R. Neuville, Electro-Mechanical Manipulator for Use in the Remote Equipment Decontamination Cell at the Defense Waste Processing Facility, Savannah River Site 12454, (2012).

[68] F. Anabitarte, A. Cobo, J.M. Lopez-Higuera, Laser-Induced Breakdown Spectroscopy: Fundamentals, Applications, and Challenges, ISRN Spectroscopy, 2012 (2012) 285240.

[69] K. Song, H. Cha, J. Lee, Y.-I. Lee, Investigation of the Line-Broadening Mechanism for LaserInduced Copper Plasma by Time-Resolved Laser-Induced Breakdown Spectroscopy, Microchemical Journal, 63 (1999) 53-60.

871 [70] M. Gaft, L. Nagli, I. Fasaki, M. Kompitsas, G. Wilsch, Laser-induced breakdown spectroscopy for 872 on-line sulfur analyses of minerals in ambient conditions, Spectrochimica Acta Part B: Atomic 873 Spectroscopy, 64 (2009) 1098-1104.

874 [71] A.C. Albrecht, On the Theory of Raman Intensities, The Journal of Chemical Physics, 34 (1961) 875 1476-1484.

876 [72] USEPA, Guidance on Systematic Planning Using the Data Quality Objectives Process (EPA 877 QA/G4), in, US Environmental Protection Agency, 2006.

878 [73] USEPA, Data Quality Objectives Process for Hazardous Waste Site Investigations (EPA QA/G879 4HW), in, US Environmental Protection Agency, 2000.

880 [74] S. Wallace, N. Smith, N. Nerantzis, Handheld methods in archaeological research on large 881 copper alloy assemblages: HH-XRF against HH-LIBS, Archaeometry, (2020). 